\title{
Synthesis and Characterisation of Promising Nanosized Flotation Reagent
}

\author{
Diana I. Saikova*a, \\ Dmitry I. Chistyakova, Svetlana V. Saikova ${ }^{a}$, \\ Yury L. Mikhlin ${ }^{\mathrm{b}}$ and Vladimir I. Kuzmin ${ }^{\mathrm{b}}$ \\ ${ }^{a}$ Siberian Federal University, \\ 79 Svobodny, Krasnoyarsk, 660041, Russia \\ ${ }^{b}$ Institute of Chemistry and Chemical Technology SB RAS \\ FRC "Krasnoyarsk Science Center SB RAS" \\ 50/24 Akademgorodok, Krasnoyarsk, 660036, Russia
}

Received 15.01.2018, received in revised form 30.01.2018, accepted 21.02.2018

Here, we examined the formation of copper nanoparticles in reaction of aqueous solutions of cupric sulfate and sodium dibutyl dithiophosphate, and characterized the products using UV-vis absorption, dynamic light scattering (DLS), zeta potential measurement, TEMandX-rayphotoelectron spectroscopy (XPS). Colloidal copper dibutyl dithiophosphate with $\left(\mathrm{C}_{4} \mathrm{H}_{9} \mathrm{O}\right)_{2} \mathrm{PSSC} \mathrm{u}^{I}$ composition and the average diameter of $40 \mathrm{~nm}$ easily formed and were stable for several days, especially if excessive dibutyl dithiophosphate was used. The size of nanoparticles was smaller at 40 degrees. The UV-vis spectra has absorption maximum at about $420 \mathrm{~nm}$. TEM micrographs and Cu $2 p, S 2 p O 1 s$ XAS spectra revealed a composition and structure of the particles.

Keywords: nanoparticles, dibutyl dithiophosphate, sols, X-ray photoelectron spectroscopy, DLS.

Citation: Saikova D.I., Chistyakov D.I., Saikova S.V., Mikhlin Yu.L., Kuzmin V.I. Synthesis and characterisation of promising nanosized flotation reagent, J. Sib. Fed. Univ. Chem., 2018, 11(1), 72-80. DOI: 10.17516/1998-2836-0059.

(C) Siberian Federal University. All rights reserved

* Corresponding author E-mail address: diana.saykova@mail.ru 


\section{Поиск оптимальных условий синтеза}

\section{и характеризация перспективного нанофлотореагента}

Д.И. Сайкова ${ }^{\mathrm{a}}$, Д.И. Чистяков ${ }^{\mathrm{a}}$, С.В. Сайкова ${ }^{a}$, Ю.Л. Михлин ${ }^{\boldsymbol{0}}$ В.И. Кузьмин

${ }^{a}$ Сибирский федеральный университет Россия, 660041, Красноярск, пр. Свободныій, 79 ${ }^{6}$ Институт химии и химической технологии СО РАН ФИЦ «Красноярский научный иентр СО РАН» Россия, 660036, Красноярск, Академгородок, 50/24

Впервые было показано, что устойчивые гидрозоли, содержащие наночастиць дибутилдитиофосфата меди, могут быть получены путем простого взаимодействия водных растворов сульфата меди и дибутилдитиофосфата натрия. В работе вылвлено влияние реакционных параметров на синтез наночастии и проведено исследование продуктов физическими методами (оптическая спектроскопия, динамическое рассеяние света, рентгеновская фотоэлектронная спектроскопия, просвечивающая электронная микроскопия). Устойчивые золи наночастии образуются при использовании избытка дибутилдитиофосфатионов и температуре синтеза $40{ }^{\circ} \mathrm{C}$. Полученные гидрозоли имеют максимум поглощения вблизи 420 нм и содержат наночастиць размером около 40 нм.

Ключевые слова: наночастицы, флотация, аэрофлоты, дибутилдитиофосфаты, поверхность, оптическая спектроскопия, динамическое рассеяние света, рентгеновская фотоэлектронная спектроскопия.

\section{Введение}

Как известно, флотация используется для обогащения полезных ископаемых, очистки промышленных стоков и воды от органических веществ и бактерий, ускорения отстаивания, выделения твердых взвесей и эмульгирования веществ.

Наиболее важное применение флотация находит в горноперерабатывающей промышленности. В настоящее время методом флотации обогащаются более 95 \% всех сульфидных руд, содержащих цветные, редкие и драгоценные металлы [1]. В качестве эффективных собирателей для флотационного процесса используются ксантогенаты и дитиофосфаты (аэрофлоты) щелочных металлов. Последние являются солями вторичных кислых сложных эфиров дитиофосфорной кислоты и какого-либо спирта, в которых один атом серы двойной связью присоединен к фосфору, а другой - связан с фосфором и водородом (рис. 1).

Аэрофлоты обладают более высокой селективностью при разделении сульфидов цветных металлов и сульфидов железа по сравнению с другими флотореагентами. Этот класс реагентов вследствие своей доступности, устойчивости, простоты обращения в промышленных условиях позволяет наиболее эффективно решать вопросы повышения качества концентратов и умень- 


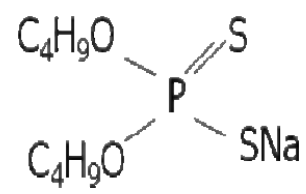

Рис. 1. Строение молекулы дибутилдитиофосфата натрия

Fig. 1. The structure of the sodium dibutyldithiophosphate

шения взаимных потерь металлов при разделении сульфидных минералов [2, 3]. Следует также заметить, что применение аэрофлотов, как правило, в небольших количествах, позволяет существенно повысить извлечение мелкодисперсных частиц, что объясняется более высокой поверхностной активностью аэрофлотов на границе газ - жидкость по сравнению, например, с ксантогенатами [1].

В процессе флотации сульфидных медных минералов с использованием дибутилдитиофосфата натрия непосредственно на поверхности минерала или в растворе могут формироваться наночастицы (нч) дибутилдитиофосфата меди, адсорбирующиеся на поверхности минерала. При этом они формируют особый микрорельеф, который может оказывать влияние на прилипание пузырька воздуха к минеральной поверхности, а следовательно, на повышение эффективности и скорости флотации [4-8].

В литературе практически отсутствуют результаты, касающиеся получения и исследования наночастиц диалкилдитиофосфатов меди. Таким образом, целями данной работы являются изучение влияния реакционных параметров (концентрации исходных веществ, их молярного соотношения, температуры) на стабильность полученных гидрозолей и размер образующихся наночастиц дибутилдитиофосфата (ДБДТФ) меди, разработка на этой основе методики их синтеза, а также исследование полученных наночастиц методами оптической спектроскопии, РФЭС и динамического рассеяния света (DLS).

\section{Экспериментальная часть}

В работе применялись следующие реагенты: сульфат меди (II) «ч.д.а.»; дибутилдитиофосфат натрия (ДБДТФ) «техн.», н-гептан, дистиллированная вода.

ДБДТФ натрия предварительно очищали, далее проводили исследование очищенного раствора на содержание общего и органического фосфора [9]. По результатам анализа чистота ДБДТФ составила $95 \%$.

Синтез наночастиц дибутилдитиофосфата меди осуществляли взаимодействием при температурах $30 \div 60{ }^{\circ} \mathrm{C}$ равных объемов водных растворов $\mathrm{CuSO}_{4}\left(\mathrm{C}=2 * 10^{-3} \mathrm{M}\right)$ и дибутилдитиофосфата натрия $\left(\mathrm{C}=1^{*} 10^{-3}-8^{*} 10^{-3} \mathrm{M}\right)$. Процесс образования золей ДБДТФ меди может быть описан уравнением

$$
4\left(\mathrm{C}_{4} \mathrm{H}_{9} \mathrm{O}\right)_{2} \mathrm{PSS}^{-}+2 \mathrm{Cu}^{2+}=2\left(\mathrm{C}_{4} \mathrm{H}_{9} \mathrm{O}\right)_{2} \mathrm{PSSCu}^{\mathrm{I}}+\left(\left(\mathrm{C}_{4} \mathrm{H}_{9} \mathrm{O}\right)_{2} \mathrm{PSS}\right)_{2} \text {. }
$$

В результате реакции (1) образуется смесь продуктов: дибутилдисульфид и дибутилдитиофосфат меди (I), которую после центрифугирования разделяли путем селективного растворения дибутилдисульфида в н-гептане.

$$
-74-
$$


Полученные гидрозоли изучали спектрофотометрически в области длин волн 200-800 нм (спектрометр Specol 1300) в кварцевой кювете с длиной оптического слоя 1 см. Для исследования методом РФЭС каплю полученного золя высушивали на пирографитовой подложке в вакууме шлюзовой камеры спектрометра SPECS, снабженного полусферическим анализатором электронов PHOIBOS 150-MCD-9. Спектры образцов записывали при возбуждении монохроматизированным излучением $\mathrm{AlK}_{\alpha}(1486,6$ эВ) и $\mathrm{Mg} \mathrm{K \alpha}(1253,6$ эВ).

Для определения гидродинамического диаметра полученных частиц использовали метод динамического светорассеяния (Zetasizer Nano ZS Malvern Instruments Ltd, Великобритания). Измерения проводили при угле рассеяния $173^{\circ}$. Размер частиц определяли как среднее из трех измерений. В качестве выходного параметра брали средний объемный размер $\left(\mathrm{Z}_{\mathrm{aver}}\right)$.

\section{Обсуждение результатов}

\section{Влияние кониентращии ДБДТФ-ионов}

В работе были проведены исследования стабильности полученных золей в зависимости от исходной концентрации ДБДТФ натрия в интервале $1 \div 8$ ммоль/л (мМ). Наиболее стабильны гидрозоли, полученные при использовании дибутилдитиофосфата натрия с концентрацией 5-8 мМ. Следует заметить, что в соответствии с реакцией (1) стехиометрической является концентрация 4 мМ, однако золи, образованные взаимодействием ДБДТФ натрия с концентрацией меньше 5 мМ, нестабильны и формируют осадок. Из этого следует, что для образования стабильных золей необходим избыток дибутилдитиофосфата натрия. Образованию дибутилдитиофосфата меди соответствует максимум поглощения в оптическом спектре при 420 нм (рис. 2).

Для исследования размера частиц золей методом динамического рассеяния света были использованы образцы с концентрацией дибутилдитиофосфата натрия 5-8 мМ. Рисунок $3 a$ характеризует распределение частиц по размерам в зависимости от концентрации дибутилдитиофосфат-ионов. Видно, что при концентрации ДБДТФ, равной 5 мМ, образуются

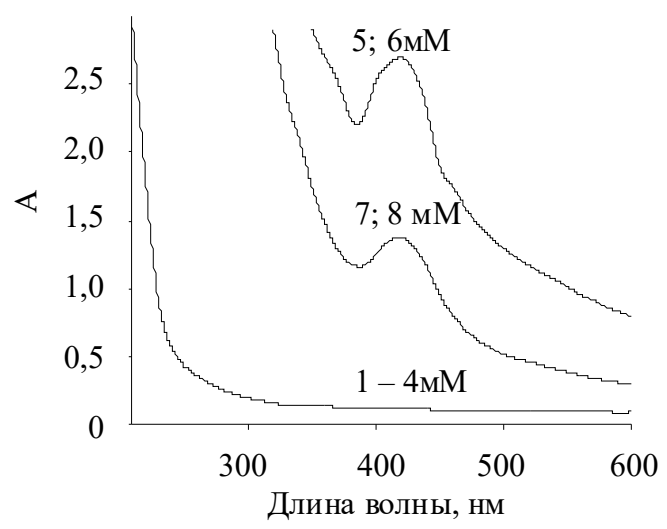

Рис. 2. Влияние концентрации дибутилдитиофосфата натрия на вид оптических спектров поглощения золей дибутилдитиофосфата меди

Fig. 2. Effect of sodium dibutyldithiophosphate concentration on UV-vis absorption spectra of copper dibutyldithiophosphate sols 

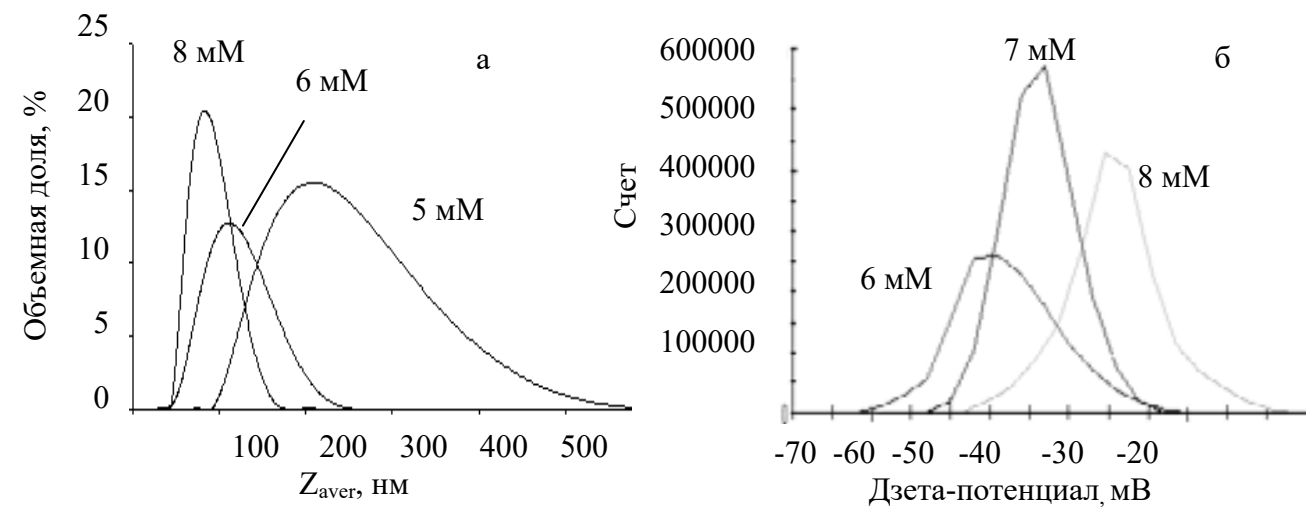

Рис. 3. Изменение гидродинамического диаметра частиц (а) и их дзета-потенциала (б) в зависимости от концентрации дибутилдитиофосфата меди

Fig. 3. The hydrodynamic diameter (a) and zeta-potential (b) of copper dibutyldithiophosphate

крупные частицы размером около 220 нм, при увеличении концентрации исходного реагента до 8 мМ наблюдается формирование более мелких частиц со средним размером 80 нм. Причиной стабилизации золей, по нашему мнению, является адсорбция анионов на поверхности частиц, что подтверждается отрицательным значением дзета-потенциала поверхности частиц, полученных при избытке ДБДТФ над стехиометрией реакции (1) (рис. 3б).

\section{Влияние температуры}

Влияние температуры на гидродинамический диаметр наночастиц различно на начальном (0-5 мин) и завершающем (10-30 мин) этапах синтеза. На первом этапе при увеличении температуры процесса с 30 до $40{ }^{\circ} \mathrm{C}$ наблюдается резкое уменьшение размера частиц (от 100 до 50 нм), дальнейший рост температуры до $60{ }^{\circ} \mathrm{C}$ приводит к увеличению их гидродинамического диаметра: при $50{ }^{\circ} \mathrm{C}$ - до 70 нм, а при $60{ }^{\circ} \mathrm{C}$ - до 80 нм (рис. $4 a$ ), при этом количество рассеивающих центров практически не зависит от температуры (рис. 46). Данная закономерность воспроизводилась в различных экспериментах, но ее причина нам пока не ясна и требует дополнительного изучения.

При увеличении продолжительности синтеза гидродинамический диаметр частиц в целом возрастает (рис. 4б), особенно заметно (от 80 до 110 нм) при температуре $60{ }^{\circ} \mathrm{C}$, причем этот рост сопровождается и увеличением числа рассеивающих центров $\mathrm{N}$ (рис. 46), что, вероятно, объясняется возрастанием выхода наночастиц дибутилдитиофосфата. Анализ вида полученных зависимостей позволяет предположить, что увеличение размера наночастиц не связано с их агломерацией, а сам процесс их роста имеет довольно значительную энергию активации.

\section{Исследование методом РФЭС}

Методом РФЭС с разрешением по глубине было проведено изучение химического состояния поверхности образцов. Исходные золи в некоторых экспериментах очищали от примеси - дисульфида - селективным растворением в н-гептане (см. выше). На основании анализа обзорных спектров (рис. 5) установили, что в них отсутствуют линии, соответствующие 

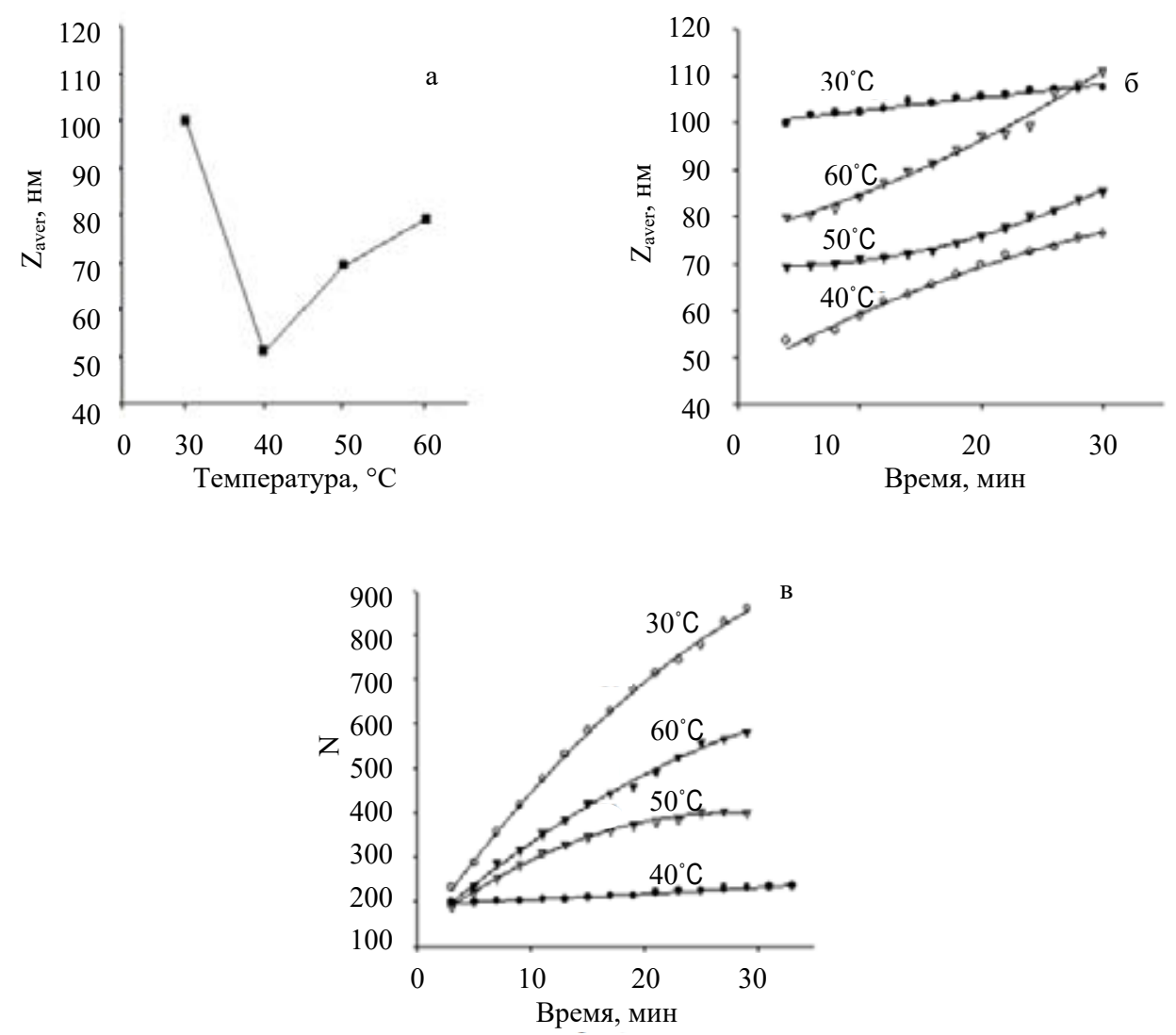

Рис. 4. Влияние температуры синтеза на динамику изменения гидродинамического диаметра частиц дибутилдитиофосфата меди (а, б) и количества рассеивающих центров (в)

Fig. 4. Time evolution of hydrodynamic diameter of the particles $(\mathrm{a}, \sigma)$ and the number of scattering centers (в) at various temperatures

натрию, что говорит о хорошей очистке образца от исходных реагентов. Элементный состав частиц неочищенных гидрозолей характерен для смеси дибутилдитиофосфата меди (I) и дисульфида, несколько обедненной (ДБДТФ) 2 (табл. 1). При этом дисульфид в основном находится в приповерхностном слое образца ( 20 \%). Возможно, вследствие его большей летучести в условиях сверхвысокого вакуума он диффундирует к поверхности образца и частично улетучивается.

В спектрах $\mathrm{Cu} 2 \mathrm{p}$, полученных при различных энергиях возбуждения, наблюдаются небольшие различия. Так, в приповерхностном слое ( $\mathrm{Mg} \mathrm{K \alpha} 1253,6$ эВ) линия $\mathrm{Cu} 2 \mathrm{p}_{3 / 2}$ состоит из основной компоненты при 932,5 эВ, характерной для соединений меди (I), слабой компоненты при 934,0 эВ и сателлитов встряски (shake-up) около 942-947 эВ небольшой интенсивности, характерных для соединений меди (II). Основной вклад соединений меди (I) также подтверждает положение пика Оже-спектра $\mathrm{Cu} \mathrm{L}_{3} \mathrm{MM}$ при 915,4 эВ (не приводится). В спектрах же более глубоких слоев образца (Al Ka 1486.74 эВ) компоненты, характерные для $\mathrm{Cu}$ (II), полностью отсутствуют. Не исключено, что медь (II) на поверхности образца присутствует в виде небольшой примеси исходной соли меди (II). 
Таблица 1. Элементный анализ полученных образцов дибутилдитиофосфата меди и дибутилдисульфида, по данным РФЭС при различной энергии возбуждения

Table 1. Elemental analysis of copper dibutyldithiophosphate and dibutyl disulfide

\begin{tabular}{|l|c|c|c|}
\hline \multirow{2}{*}{ Образец } & \multicolumn{2}{|c|}{ Атомные доли элементов, \% } \\
\cline { 2 - 4 } & $\mathrm{Cu}$ & $\mathrm{S}$ & $\mathrm{P}$ \\
\hline Неочищенный образец & & & 1,5 \\
$\mathrm{MgK \alpha}(1253,6$ эВ) & 1,0 & 2,8 & 1,2 \\
$\mathrm{~A} 1 \mathrm{K \alpha}(1486,74$ эВ) & 1,0 & 2,1 & 2,1 \\
\hline (ДБДТФ) & 0,05 & 4,1 & 2 \\
\hline (ДБДТФ) ${ }_{2}$ расч. & 0 & 4 & 0,9 \\
\hline СиДБДТФ & 1,0 & 2,2 & 1,0 \\
\hline СиДБДТФ (расч.) & 1,0 & 2,0 & \\
\hline
\end{tabular}
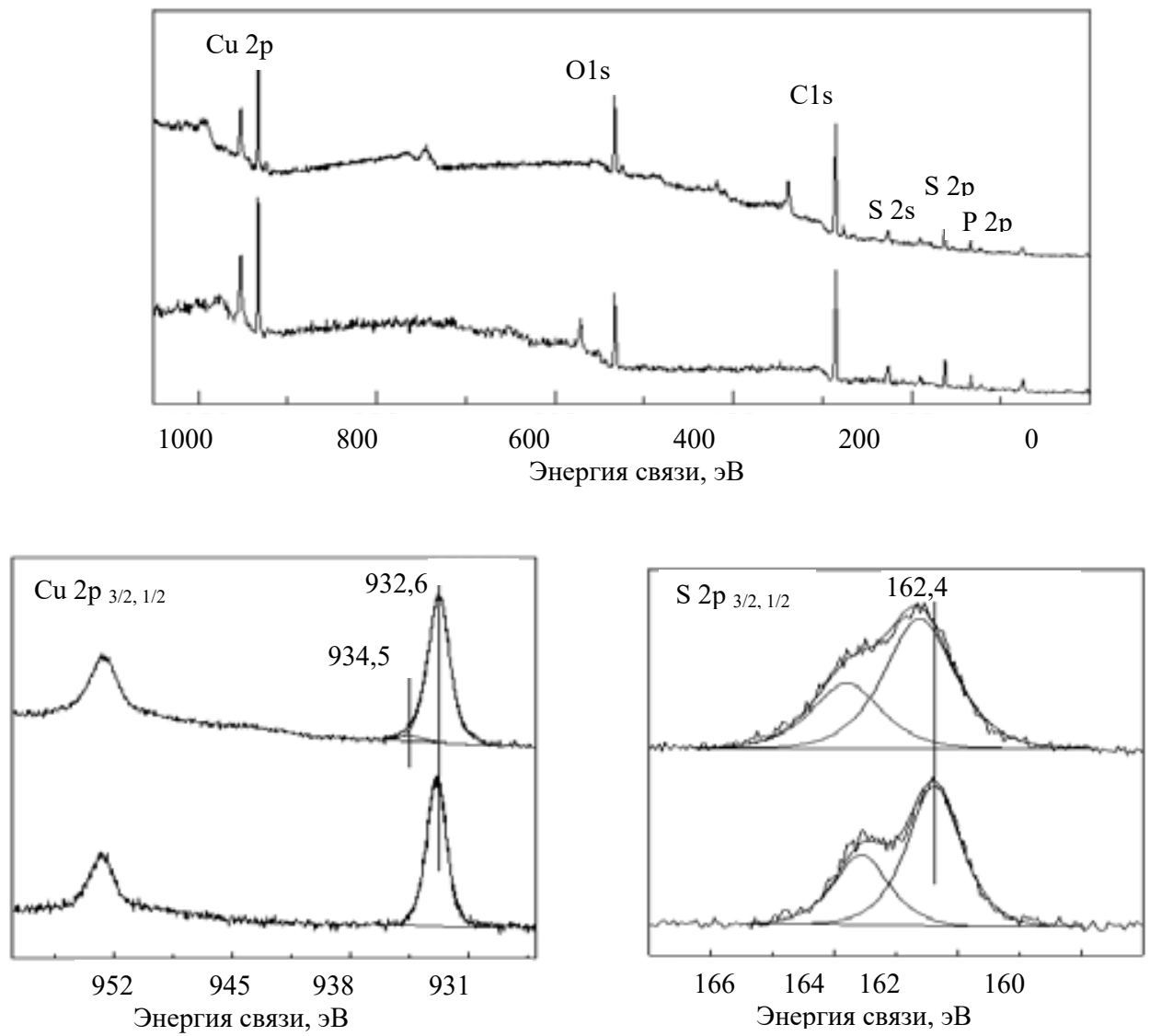

Рис. 5. Рентгенофотоэлектронные спектры неочищенных золей дибутилдитиофосфата меди

Fig. 5. X-ray photoelectronic spectra of copper dibutyldithiophosphate 


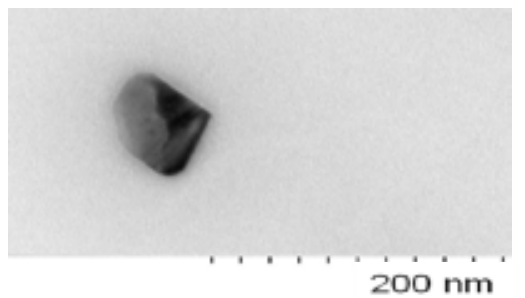

Рис. 6. Микрофотография (ПЭМ) наночастиц дибутилдитиофосфата меди

Fig. 6. Typical TEM micrographs of copper dibutyldithiophosphatenanoparticles

Линия S 2p может быть разложена на две компоненты: основную с энергией связи 162,4 эВ и второстепенную (вклад около 5 \%) при 163,6 эВ, что хорошо согласуется с ранее опубликованными данными для исходных алкилдитиофосфатов. Линия O 1s (не приводится) состоит из двух компонент при 532,7 эВ и 531,1 эВ, отвечает группе -С-О-Р- и, возможно, частично окисленной группе фосфора -P=O/-Р-О- соответственно. Спектр C 1s (не приводится) содержит линии алифатического углерода при 285,0 эВ (- $\left.\mathrm{CH}_{2}-\right)$, эфирной группы около 286,5 эВ (- $\mathrm{CH}_{2}$-О-) и слабой возможно карбоксильных групп 288,6 эВ (-С-(О)О-), что характерно для дитиофосфата меди (I).

На рис. 6 приведена микрофотография (просвечивающая электронная микроскопия) синтезированных частиц. Видно, что формируются кристаллиты тетраэдрической формы размером около 40 нм.

\section{Заключение}

В ходе исследования изучено влияние различных факторов на процесс получения наночастиц дибутилдитиофосфата меди (I) и определены условия синтеза стабильных гидрозолей: концентрация меди $2 \mathrm{мM}$, дибутилдитиофосфата натрия - 6-8 мМ, температура $40{ }^{\circ} \mathrm{C}$, время синтеза 10-15 мин. Полученные гидрозоли имеют максимум поглощения при 420 нм. Гидродинамический диаметр полученных наночастиц в зависимости от условий синтеза варьирует в интервале от 50 до 100 нм. По результатам просвечивающей электронной микроскопии кристаллиты имеют тетраэдрическую форму и средний размер 40 нм. При исследовании полученных частиц методом РФЭС подтверждено образование двух продуктов синтеза: дибутилдитиофосфата меди состава $\left(\mathrm{C}_{4} \mathrm{H}_{9} \mathrm{O}\right)_{2} \mathrm{PSSCu}^{\mathrm{I}}$ и дибутилдисульфида, которые могут быть разделены селективным растворением в н-гептане.

Статья подготовлена по материалам доклада, представленного на IХ международном конгрессе «Цветные металлы и минераль-2017».

\section{Список литературы}

1. Рябой В.И., Асончик К.М., Полькин В.Н., Полтавская Л.М., Репина Н.В. Применение селективного собирателя при флотации медно-цинковых руд. Обогащение руд, 2008. № 3, С. 20 22. [Rjaboj V.I., Asonchik K.M., Pol'kin V.N., Poltavskaja L.M., Repina N.V. Application of selective collector in the flotation of copper-zinc ores. Enrichment of ores, 2008. Vol. 3, P. 20-22. (In Russ.)]. 
2. Асончик К.М., Полькин В.Н., Старостин Ю.И., Репина Н.В. Повышение качества медного концентрата при флотации медно-цинковых руд Гайского месторождения. Обогащение руд. 2006. № 6, C. 7-9. [Asonchik K.M., Pol'kin V.N., Starostin Ju.I., Repina N.V., Improving the quality of copper concentrate in the flotation of copper-zinc ores Gajskoe field. Enrichment of ores. 2006. Vol. 6, Р. 7-9. (In Russ.)].

3. Рябой В.И., Шендерович В. А., Кретов В.П. Применение аэрофлотов при флотации руд. Обогащение руд. 2005. № 6, C. 43-44. [Rjaboj V.I., Shenderovich V.A., Kretov V.P. Application aerofloats in the flotation of ores. Enrichment of ores. 2005. Vol. 6, P. 43-44. (In Russ.)].

4. Vorobyev S.A., Saikova S.V., Erenburg S.B., Trubina S.V., Ivanov Yu.N., Maksimov N.G., Mikhlin Yu.L., Journal of Structural Chemistry. November 2017, Vol. 58, Issue 6, P. 1144-1151.

5. Mikhlin Yu.L., Romanchenko A.S., Vorobyev S.A., Karasev S.V., Volochaev M., Kamenskiy E., Burdakova E. Ultrafine particles in ground sulfide ores: A comparison of four $\mathrm{Cu}-\mathrm{Ni}$ ores from Siberia, Russia. Ore Geology Review. 2017, Vol. 81, P. 1-9.

6. Mikhlin Yu.L., Vorobyev S.A., Karasev S.V., Romanchenko A.S., Karacharov A.A., Kamensky E.S., Burdakova E.A. Composition and properties of highly dispersed particles generated under sulfide ore milling. Journal of Mining Science. 2016, Vol. 52, Issue 5, P. 982-988.

7. Yang S., Pelton R., Raegen A., Montgomery M., Dalnoki-Veress K. Nanoparticle flotation collectors: Mechanisms Behind a New Technology. Langmuir. 2011, Vol. 17, P. 10438-10446.

8. Dong X., Heera S.M., Emily D.C., Pelton R.H. Relating nanoparticle shape and adhesiveness to performance as flotation collectors. Ind. Eng. Chem. Res. 2016, Vol. 55, P. 9633-9638.

9. РД 52.24.452-2011. [GD 52.24.452-2011]. 